\title{
Evaluation of Clinical and Imaging Findings in Children with Diagnosis of Acute Appendicitis
}

\author{
Aytekin Kaymakci, ${ }^{1}$ Sirin Guven, ${ }^{2}$ Seher Erdogan, ${ }^{3}$ Ilhan Ciftci, ${ }^{4,}$ and Recai Gokcan ${ }^{5}$ \\ ${ }^{1}$ Department of Pediatric Surgery, Umraniye Training and Research Hospiatal, Turkey \\ ${ }^{2}$ Department of Pediatrics, Umraniye Training and Research Hospiatal, Turkey \\ ${ }^{3}$ Division of Pediatric Intensive Care Unite, Umraniye Training and Research Hospiatal, Turkey \\ ${ }^{4}$ Department of Pediatric Surgery, Selcuk University Medical Faculty, Turkey \\ ${ }^{5}$ Department of Radyology, Umraniye Training and Research Hospiatal, Turkey \\ "Corresponding author: Ilhan Ciftci, Selcuk Universitesi Tip Fakultesi, Cocuk Cerrahisi A. D. , Konya, Turkey. Tel: +90-3322415000, E-mail: driciftci@yahoo.com
}

Received 2016 December 19; Revised 2017 February 16; Accepted 2017 April 14.

\begin{abstract}
Objectives: This study is an evaluation of the accuracy of ultrasonography (USG), computed tomography (CT), and Alvarado score (AS) in the diagnosis and management of acute appendicitis in children.

Methods: Records of pediatric patients admitted to the pediatric emergency department (ED) between 2008 and 2012 were evaluated retrospectively. Patient data from the national electronic health information system was screened and those with complete clinical and imaging findings (AS, preoperative USG and/or CT images) and postoperative pathological diagnosis were included in the study.

Results: Study group consisted of 449 children with diagnosis of suspected acute appendicitis aged between 3 and 15 years (mean age: $9.20 \pm 2.73$ years). Of the total, 428 (95.3\%) patients underwent appendectomy and 21 (4.7\%) cases were treated conservatively. Mean duration of symptoms was $4.94 \pm 1.84$ hours. Pathological evaluation results were negative (i.e., removal of normal appendix) in $36(8.4 \%)$ patients; histopathological diagnosis was acute appendicitis in 392 (91.6\%) patients. Perforated appendix was found in $38(8.5 \%)$ patients. In patients with histopathologically confirmed appendicitis, sensitivity, specificity, positive predictive value (PPV), and negative predictive value (NPV) of CT in diagnosis of acute appendicitis were $96.3 \%, 55.6 \%, 92.8 \%$, and $71.4 \%$, respectively. Sensitivity, specificity, PPV, and NPV of USG were 73.5\%, 22.2\%, 91.1\%, and 69.2\%, respectively. Negative appendectomy rate was $6.4 \%$ (n $=8)$ in patients who had preoperative CT scan, and 6.5\% $(n=28)$ in patients who had USG examination.

Conclusions: CT has higher sensitivity than USG in diagnosis of acute appendicitis. USG, on the other hand, is widely accessible method and does not use ionizing radiation. Therefore, it may be used as initial radiological imaging method in acute appendicitis. Thin-filter, contrast-unenhanced CT scans may be preferred in cases where clinical signs and USG findings are unclear or controversial.
\end{abstract}

Keywords: Alvarado score, Appendicitis, Computed tomography, Ultrasonography, Children

\section{Background}

Acute appendicitis is one of the most common reasons for emergency abdominal surgery in children. The nonspecific nature of complaints and variability may delay correct diagnosis and lead to larger number of cases with perforation.

Research on comparison of clinical scores and imaging findings continues in order to decrease negative appendectomy rate $(1,2)$. According to recent studies, Alvarado score (AS) is a useful tool in evaluation of children with possible appendicitis. Score of 4 or less is used to rule out appendicitis, whereas score of 8 or higher suggests appendicitis and need for appendectomy/surgical consultation. Patients with AS of between 5 and 7 are potential candidates for further radiological work-up. Although appendicitis score has improved clinical diagnostic accuracy for diagnosis of appendicitis from $80 \%$ to $92 \%$, frequency of unnecessary appendectomies is still high, between $8.8 \%$ and 34\% (3-5).

\section{Objectives}

The aim of this study was to evaluate the sensitivity and specificity of ultrasonography (USG), computed tomography (CT) and Alvarado score (AS) in diagnosis of acute appendicitis in children.

\section{Methods}

The study group consisted of children who were admitted to pediatric emergency department of Umraniye training and research hospital between August 2008 and April 2012 for abdominal pain of less than 5 days' duration 
and with clinical diagnosis of acute appendicitis. Demographic data, clinical findings, laboratory values, preoperative USG and/or CT imaging findings, and postoperative pathological findings were obtained from electronic national health information system (NHIS) medical records. AS and duration of symptoms were recorded for each patient. AS was calculated as follows: Presence of fever $\geq$ $37.3^{\circ} \mathrm{C}$ (1 point), rebound tenderness (1 point), right-lowerquadrant tenderness ( 2 points), anorexia (1 point), nausea and/or vomiting (1 point), migration of pain (1 point), leukocytosis $>10,000$ cells $/ \mathrm{mm}^{3}$ ( 2 points), and polymorphonuclear neutrophils $>7500$ cells $/ \mathrm{mm}^{3}$ ( 1 point). Patients were then divided into 3 groups: Group 1 was made up of patients with high (> 8) AS, Group 2 consisted of patients with intermediate (5-7) AS and Group 3 comprised patients with low $(<4)$ AS. Preoperative USG and/or CT image findings and postoperative pathological report findings were also recorded. Pathological evaluation results were negative (removal of normal appendix), acute appendicitis, or perforated appendix. USG studies were performed in emergency department following physical examination and during observation period for acute appendicitis. CT was performed only for patients with clinical findings of acute appendicitis and negative USG image. USG and only CT findings were recorded as negative or positive for appendicitis. CT scan was performed without contrast, equivocal non-contrast $\mathrm{CT}$ results and repeated CT scans were not reported in our patient records. USG examination was performed using Aplio MX (Toshiba medical systems corp., Otawara-shi, Japan) color Doppler ultrasonography device, equipped with convex and linear transducers. Findings supportive of diagnosis of appendicitis included pain; aperistaltic, noncompressible, dilated appendix ( $>6 \mathrm{~mm}$ outer diameter); presence of appendicolith (calcified deposit within the appendix); and prominent echogenic pericecal fat. CT evaluation was conducted using spiral tomography scanner (GE medical system, optima CT 660,128 Slice USA). Presence of dilated appendix with distended lumen (> $6 \mathrm{~mm}$ diameter), thickened wall, and periappendiceal inflammation with stranding of adjacent fat and thickening of lateroconal fascia were considered signs of appendicitis (Figure 1). USG and CT images were interpreted by radiologists. Percentage of cases of pathologically proven negative or acute appendicitis in children who had USG without CT examination was compared with that of children who had USG and CT examination. Patients who did not undergo surgery were clinically observed in emergency department (ED).

\subsection{Statistical Analyses}

SPSS Statistics 22.0 (IBM Corp., Armonk, NY, USA) was used for statistical analyses. Data were analyzed using

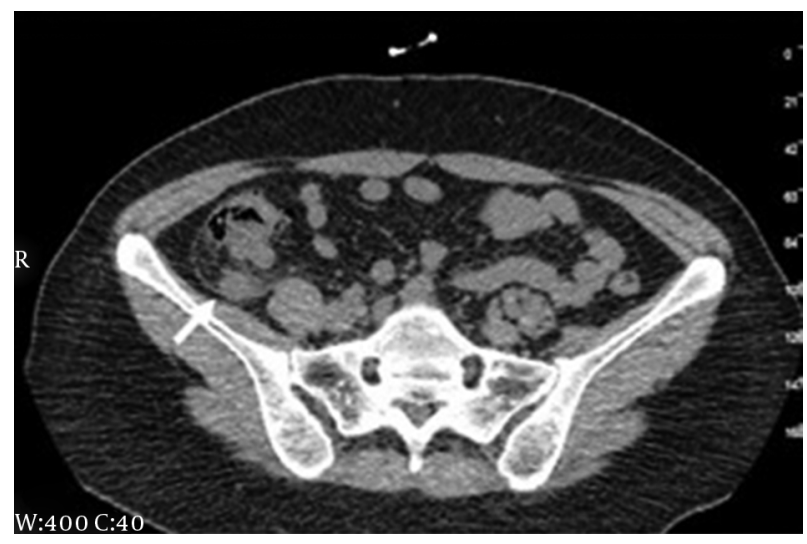

Figure 1. Unenhanced Axial CT Image: Increased Diameter of Appendix (11 mm) and Inflammation in Periappendiceal Mesentery

descriptive statistical methods (i.e., mean, SD, frequency). Comparisons between study groups were performed using Mann-Whitney U test for continuous variables. McNemar's test was applied to test difference between paired proportions. Sensitivity, specificity, positive predictive value (PPV) and negative predictive value (NPV) of diagnostic modalities were calculated. Level of statistical significance was set at $\mathrm{P}<0.05$.

\section{Results}

Study included 449 children with suspected diagnosis of acute appendicitis. Mean age of the patients was $9.20 \pm$ 2.73 years. There were 208 (46.3\%) female patients and 241 (53.7\%) male patients. There was evidence of perforation in $38(8.5 \%)$ patients. Of the total, 428 (95.3\%) patients had appendectomy and 21 (4.7\%) patients were managed conservatively. Mean duration of symptoms was $4.94 \pm 1.84$ hours, with median duration of 4 hours. Pathological results were negative (i.e., removal of normal appendix) in 36 (8.4\%) patients, whereas histopathology was consistent with acute appendicitis in 392 (91.6\%) patients. Pathological and imaging findings are summarized in Table 1.

In $25(5.6 \%)$ patients, AS was < 4, and these patients were not evaluated with CT scan. One patient with AS of 3 had muscular defense during physical examination. This patient also had normal USG examination, but subsequently had surgery and was diagnosed histopathologically as appendicitis.

CT scan was performed on 125 patients, of whom 111 ( $89 \%$ ) had positive CT findings. Eight (6.4\%) patients had histopathological diagnosis of negative for appendicitis. Fourteen (11.2\%) patients had negative CT findings; however, $4(3.2 \%)$ of them were histopathologically diagnosed 
Table 1. The Distribution of USG, CT and Histopathological Results in Patients

\begin{tabular}{|ccc|}
\hline & $\mathbf{n}$ & $\%$ \\
\hline USG $(\mathbf{n}=\mathbf{4 4 9})$ & & \\
\hline Positive & 316 & 70.4 \\
\hline Negative & 133 & 29.6 \\
\hline $\mathbf{C T}(\mathbf{n}=\mathbf{1 2 5})$ & & \\
\hline Positive & 111 & 88.8 \\
\hline Negative & 14 & 11.2 \\
\hline Histopathology $(\mathbf{n}=\mathbf{4 2 8})$ & & \\
\hline Appendicitis & 392 & 91.6 \\
\hline Normal & 36 & 8.4 \\
\hline
\end{tabular}

as appendicitis (Figure 3). There were 316 (73.8\%) patients with positive USG findings; however, 28 (6.5\%) of them were histopathologically normal. Of $112(26.2 \%)$ patients with negative USG results, 104 (24.3\%) were subsequently diagnosed as appendicitis.

There were 308 (68.6\%) patients with AS of between 5 and 7, CT scan was performed on 79 of these patients. There were 116 (25.8\%) patients with AS of $\geq 8$. CT scan was performed on 46 patients; 80 (69\%) patients with AS of $\geq 8$ had been diagnosed histopathologically as appendicitis and 36 (31\%) had normal histopathology. Sensitivity, PPV, and accuracy of CT scan in diagnosing acute appendicitis were each $100 \%$ in patients with AS of 8 or above. For all patients with histopathologically confirmed appendicitis, sensitivity of CT was $96.26 \%$ and specificity was $55.56 \%$; sensitivity of USG in that group of patients was $73.47 \%$ and specificity 22.22\%. USG findings, CT results, and AS of histopathologically confirmed appendicitis cases are provided in Table 2. A statistically significant difference was not found between USG-positive and USG-negative patients with respect to AS ( $\mathrm{P}>0.05 ; \mathrm{P}=0.113)$. AS of CT-positive patients, on the other hand, was significantly higher than that of CTnegative patients $(\mathrm{P}<0.01 ; \mathrm{P}=0.001)$. AS of patients diagnosed histopathologically as appendicitis was also significantly higher than score of patients with histopathologically negative diagnosis $(\mathrm{P}<0.01 ; \mathrm{P}=0.001)$ (Figure 2 ).

\section{Discussion}

Negative appendectomy rate varies significantly by patient sex. Primary reason is overlap with symptoms of acute gynecological diseases, making clinical symptoms unreliable. Overall negative appendectomy rate (8.6\%) of the present study is similar to rates reported in the relevant literature $(6,7)$. Although intravenous iodinated contrast agents may have serious side effects and CT scan itself is costly, CT may provide evidence of early stage of appendicitis and its complications (8). Non-contrast-enhanced, thin-section CT is faster and safer alternative to enhanced CT scan, and is preferred as standard technique at our institution. According to Malone and Wolf (9), non-contrast, thin section helical CT technique has $97 \%$ specificity and $87 \%$ sensitivity in patients with acute pain in right lower quadrant. Kim et al. (10) evaluated 891 young adults with suspected appendicitis and compared low-dose CT (onequarter of standard dose) to high-dose CT. Rate of negative appendectomy in 2 groups was similar and no difference was seen in terms of perforation rate. In a retrospective study conducted by Martin and Vollman (11), use of USG to evaluate suspected appendicitis decreased from $20 \%$ in 1998 to $7 \%$ in 2001. Meanwhile, CT orders increased from $17.6 \%$ to $51.3 \%$. Negative appendectomy rate was $22 \%$ for USG and $18 \%$ for CT. According to Garcia Pena et al. (12), negative appendectomy rate was $6 \%$ for patients who had preoperative CT examination and $12 \%$ for patients without prior CT examination. In the present study, negative appendectomy rate of patients who had positive CT (6.4\%) was similar to that of studies summarized above. Negative appendectomy in our patients who had positive USG rate (6.5\%) was found to be lower than reported in these studies. We did not find a difference in negative appendectomy rates based on imaging scan. Karakas et al. (13) reported higher rate of perforation in children who had only CT (54\%), or CT and USG (71\%), than in children who underwent only USG (23\%). They explained their observation with delay in management due to lengthy $\mathrm{CT}$ request to report cycle. In our study, perforated appendix was found in 38 (8.5\%) patients. Although the present study also indicates higher perforation rate in patients who underwent CT scan, time metrics regarding request to report time were not recorded, and such an inference cannot be confidently established. According to previous studies $(14,15)$, most diagnostic delay is rooted in delayed presentation of patient; delays due to hospital procedures are not significant contributors to incidence of perforation. Perforation is a serious complication of acute appendicitis, and is observed $20 \%$ more frequently in children and elderly patients $(16,17)$. Time from onset of symptoms to emergency admission was $4.94 \pm$ 1.84 hours. Relatively low rate of perforation in this study may be due to short interval between onset of symptoms and admission.

In a recent study, sensitivity and specificity of CT and USG in diagnosing appendicitis in 211 children were similar for cases with an AS of 6 or less, When AS was $\geq 6$, and USG findings conflicted with clinical findings, sensitivity and specificity of CT was higher (18). In the present study, specificity of CT was $93.4 \%$ in patients with AS of between 5 and 7 and $100 \%$ in patients with AS of 8 or more. No significant 


\section{Alvarado Score}
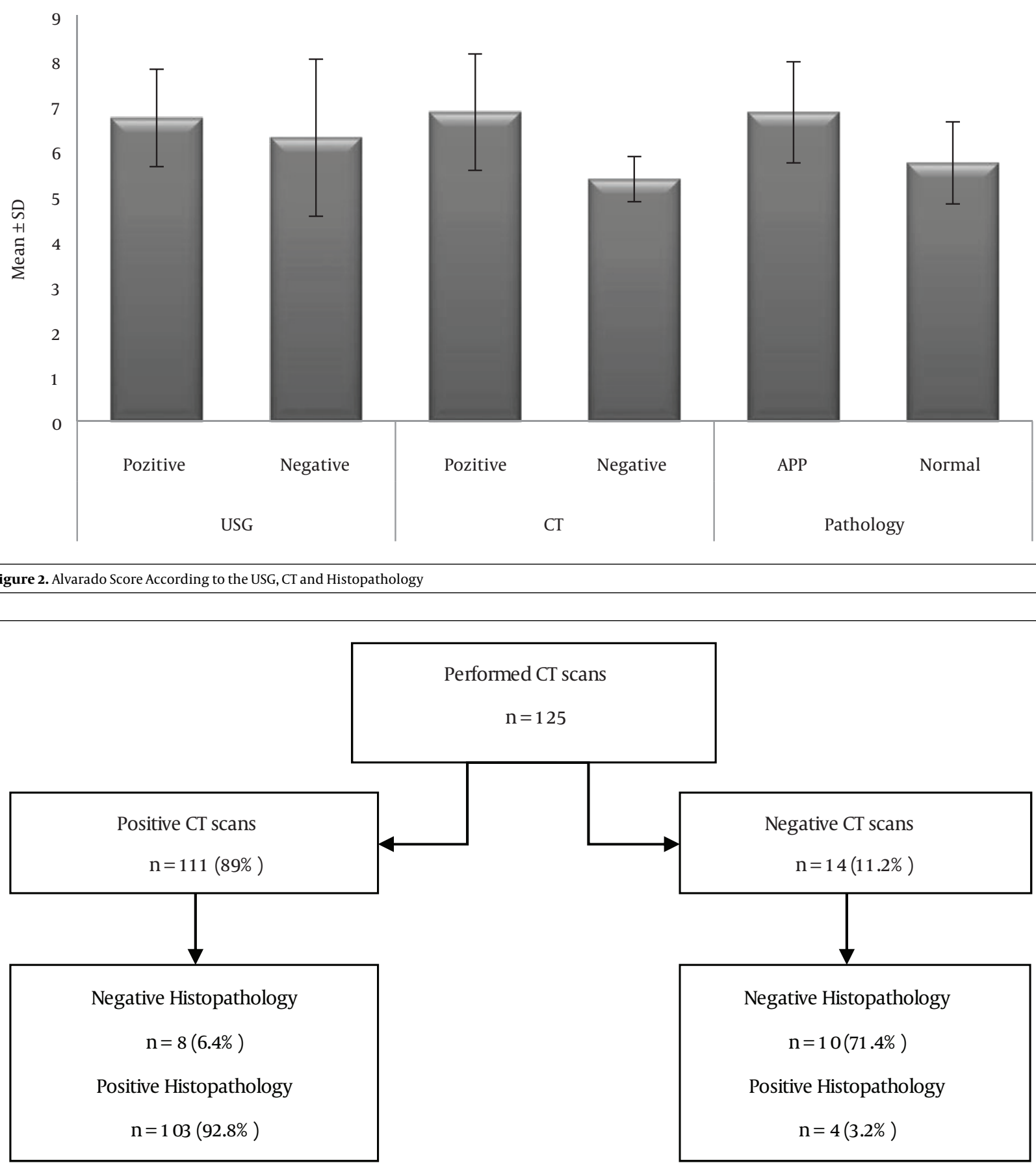

Figure 3. The Distribution of CT Results in Patients

difference was found between patients with negative and positive USG findings with regard to AS. However, patients with positive CT finding and histopathological confirmation had significantly higher AS. In a systematic review con- 
Table 2. USG and CT results in Histopathological Confirmed Appendicitis Patients According to Alvarado Scores

\begin{tabular}{|c|c|c|c|c|c|}
\hline & Sensitivity & Specificity & PPV & NPV & Accuracy \\
\hline \multicolumn{6}{|l|}{ All cases } \\
\hline CT & 96.26 & 55.56 & 92.79 & 71.43 & 90.4 \\
\hline USG & 73.47 & 22.22 & 91.14 & 7.14 & 69.2 \\
\hline \multicolumn{6}{|c|}{ Alvarado score 5 - 7} \\
\hline CT & 93.44 & 55.56 & 87.69 & 71.43 & 84.8 \\
\hline USG & 79.27 & 24.24 & 89.71 & 12.31 & 73.4 \\
\hline \multicolumn{6}{|c|}{ Alvarado score $\geq 8$} \\
\hline CT & 100 & - & 100 & - & 100 \\
\hline USG & 60.34 & - & 100 & 0 & 60.3 \\
\hline
\end{tabular}

ducted previously, sensitivity and specificity of USG in diagnosis of acute appendicitis were reported as $83.7 \%$ and $95.9 \%$, respectively $(19,20)$. Contrary to these results, we found sensitivity and specificity of USG to be $73.4 \%$ and $22.2 \%$, respectively. PPV of USG was $91.14 \%$, NPV 71.4\%, and accuracy $69.2 \%$. Sensitivity of USG was $79.2 \%$ in patients with AS of between 5 and 7, and $60.4 \%$ in patients with AS of 8 or more.

Similar to our study, Schuh et al reported a suboptimal accuracy rate (60\%) of screening with ultrasound scanning for appendicitis (21). Recent study showed that the serial US has a higher diagnostic accuracy than initial US (22). First reason for our lower specificity and accuracy may be due to using only initial US in ED. Second reason may be that even though US was performed by experienced radiologists at ED, the time for evaluation was not enough.

In conclusion, when compared with USG, CT has greater sensitivity in diagnosis of acute appendicitis. However, USG must still be initial imaging study ordered due to ease of use, and use of non-ionizing radiation. Thinsection, non-enhanced CT can be ordered if clinical signs and USG findings are contrary. Contrast-enhanced CT may be preferred if the appendix cannot be visualized with USG in patients with equivocal clinical findings.

\section{References}

1. Bhatt M, Joseph L, Ducharme FM, Dougherty G, McGillivray D. Prospective validation of the pediatric appendicitis score in a Canadian pediatric emergency department. Acad Emerg Med. 2009;16(7):591-6. doi: 10.1111/j.1553-2712.2009.00445.x. [PubMed: 19549016].

2. Goldman RD, Carter S, Stephens D, Antoon R, Mounstephen W, Langer JC. Prospective validation of the pediatric appendicitis score. J Pediatr. 2008;153(2):278-82. doi: 10.1016/j.jpeds.2008.01.033. [PubMed: 18534219].

3. Alvarado A. A practical score for the early diagnosis of acute appendicitis. Ann Emerg Med. 1986;15(5):557-64. [PubMed: 3963537].

4. Lintula H, Kokki H, Kettunen R, Eskelinen M. Appendicitis score for children with suspected appendicitis. A randomized clinical trial.
Langenbecks Arch Surg. 2009;394(6):999-1004. doi: 10.1007/s00423008-0425-0. [PubMed: 18841382].

5. Schneider C, Kharbanda A, Bachur R. Evaluating appendicitis scoring systems using a prospective pediatric cohort. Ann Emerg Med. 2007;49(6):778-84. doi: 10.1016/j.annemergmed.2006.12.016. [PubMed: 17383771] 784 e1.

6. Bergeron E. Clinical judgment remains of great value in the diagnosis of acute appendicitis. J Can Chir. 2006;49:96-100.

7. Applegate KE, Sivit CJ, Salvator AE, Borisa VJ, Dudgeon DL, Stallion $\mathrm{AE}$, et al. Effect of cross-sectional imaging on negative appendectomy and perforation rates in children. Radiology. 2001;220(1):103-7. doi: 10.1148/radiology.220.1.ro1jl17103. [PubMed: 11425980].

8. Lane MJ, Katz DS, Ross BA, Clautice-Engle TL, Mindelzun RE, Jeffrey RJ. Unenhanced helical CT for suspected acute appendicitis. AJR Am J Roentgenol. 1997;168(2):405-9. doi: 10.2214/ajr.168.2.9016216. [PubMed: 9016216].

9. Malone AJ, Wolf CR, Malmed AS, Melliere BF. Diagnosis of acute appendicitis: value of unenhanced CT. AJR Am J Roentgenol. 1993;160(4):7636. doi: 10.2214/ajr.160.4.8456661. [PubMed: 8456661].

10. Kim K, Kim YH, Kim SY, Kim S, Lee Y], Kim KP, et al. Low-dose abdominal CT for evaluating suspected appendicitis. $N$ Engl J Med. 2012;366(17):1596-605. doi: 10.1056/NEJMoa1110734. [PubMed: 22533576].

11. Martin AE, Vollman D, Adler B, Caniano DA. CT scans may not reduce the negative appendectomy rate in children. J Pediatr Surg. 2004;39(6):886-90. [PubMed: 15185219] discussion 886-90.

12. Garcia Pena BM, Mandl KD, Kraus SJ, Fischer AC, Fleisher GR, Lund DP, et al. Ultrasonography and limited computed tomography in the diagnosis and management of appendicitis in children. JAMA. 1999;282(11):1041-6. [PubMed: 10493202].

13. Karakas SP, Guelfguat M, Leonidas JC, Springer S, Singh SP. Acute appendicitis in children: comparison of clinical diagnosis with ultrasound and CT imaging. Pediatr Radiol. 2000;30(2):94-8. doi: 10.1007/s002470050023. [PubMed: 10663520].

14. Petrosyan M, Estrada J, Chan S, Somers S, Yacoub WN, Kelso RL, et al. CT scan in patients with suspected appendicitis: clinical implications for the acute care surgeon. Eur Surg Res. 2008;40(2):211-9. doi: 10.1159/000110863. [PubMed: 17998781].

15. Hernandez JA, Swischuk LE, Angel CA, Chung D, Chandler R, Lee S. Imaging of acute appendicitis: US as the primary imaging modality. Pediatr Radiol. 2005;35(4):392-5. doi: 10.1007/s00247-004-1372-8. [PubMed: 15635471].

16. Al-Khayal KA, Al-Omran MA. Computed tomography and ultrasonography in the diagnosis of equivocal acute appendicitis. A metaanalysis. Saudi Med J. 2007;28(2):173-80. [PubMed: 17268692]. 
17. Bendeck SE, Nino-Murcia M, Berry GJ, Jeffrey RJ. Imaging for suspected appendicitis: negative appendectomy and perforation rates. Radiology. 2002;225(1):131-6. doi: 10.1148/radiol.2251011780. [PubMed: 12354996].

18. Srinivasan A, Servaes S, Pena A, Darge K. Utility of CT after sonography for suspected appendicitis in children: integration of a clinical scoring system with a staged imaging protocol. Emerg Radiol. 2015;22(1):31-42. doi: 10.1007/s10140-014-1241-1. [PubMed: 24917390].

19. McKay R, Shepherd J. The use of the clinical scoring system by Alvarado in the decision to perform computed tomography for acute appendicitis in the ED. Am J Emerg Med. 2007;25(5):489-93. doi: 10.1016/j.ajem.2006.08.020. [PubMed: 17543650].
20. Doria AS, Moineddin R, Kellenberger CJ, Epelman M, Beyene J, Schuh $S$, et al. US or CT for Diagnosis of Appendicitis in Children and Adults? A Meta-Analysis. Radiology. 2006;241(1):83-94. doi: 10.1148/radiol.2411050913. [PubMed: 16928974]

21. Schuh S, Man C, Cheng A, Murphy A, Mohanta A, Moineddin R, et al. Predictors of non-diagnostic ultrasound scanning in children with suspected appendicitis. J Pediatr. 2011;158(1):112-8. doi: 10.1016/j.jpeds.2010.07.035. [PubMed: 20828717].

22. Schuh S, Chan K, Langer JC. Properties of serial ultrasound clinical diagnostic pathway in suspected appendicitis and related computed tomography use. Acad Emerg Med. 2015;22:406-14. 